\title{
Encoding Processes during Retrieval Tasks
}

\section{Citation}

Buckner, Randy L., Mark E. Wheeler, and Margaret A. Sheridan. 2001. "Encoding Processes During Retrieval Tasks." Journal of Cognitive Neuroscience 13 (3) (April): 406-415. doi:10.1162/08989290151137430.

\section{Published Version}

doi:10.1162/08989290151137430

\section{Permanent link}

http://nrs.harvard.edu/urn-3:HUL.InstRepos:33896765

\section{Terms of Use}

This article was downloaded from Harvard University's DASH repository, and is made available under the terms and conditions applicable to Other Posted Material, as set forth at http:// nrs.harvard.edu/urn-3:HUL.InstRepos:dash.current.terms-of-use\#LAA

\section{Share Your Story}

The Harvard community has made this article openly available.

Please share how this access benefits you. Submit a story.

\section{Accessibility}




\title{
Encoding Processes during Retrieval Tasks
}

\author{
Randy L. Buckner, Mark E. Wheeler, and Margaret A. Sheridan
}

\begin{abstract}
Episodic memory encoding is pervasive across many kinds of task and often arises as a secondary processing effect in tasks that do not require intentional memorization. To illustrate the pervasive nature of information processing that leads to episodic encoding, a form of incidental encoding was explored based on the "Testing" phenomenon: The incidentalencoding task was an episodic memory retrieval task. Behavioral data showed that performing a memory retrieval task was as effective as intentional instructions at promoting episodic encoding. During fMRI imaging, subjects viewed old and new words and indicated whether they remembered them. Relevant to encoding, the fate of the new words was examined using a second, surprise test of recognition after the
\end{abstract}

\section{INTRODUCTION}

Attempts to specify the processes and neural activity patterns associated with episodic memory encoding confront a difficult theoretical issue: Memory encoding is pervasive and may be encouraged in numerous kinds of cognitive tasks that differ widely in their nominal task demands. For example, memory encoding occurs as a by-product of many task situations including-but clearly extending beyond-the intent to remember (Craik \& Tulving, 1975; Hyde \& Jenkins, 1973; Walsh \& Jenkins, 1973; Craik \& Lockhart, 1972; Postman, 1964). Moreover, task demands that tend not to encourage episodic encoding will still promote poor levels of memorization even if the intent to remember is added (Hyde \& Jenkins, 1973). Thus, the immediate task goal is insufficient to infer the presence of processes associated with memory encoding. Rather, processes associated with encoding are inferred by the relation between task demands at one point in time (the study phase) and their influence on subsequent memorability at a later time (the test phase).

Consistent with process-based accounts of encoding, it has been well established that, under certain conditions, acts of memory retrieval encourage further episodic memory encoding (e.g., Roediger \& Payne, 1982; Whitten, 1978; Whitten \& Bjork, 1977; Klee \& Gardiner, 1976; see Glover, 1989 for review). Episodic retrieval

Washington University, Howard Hughes Medical Institute imaging session. fMRI analysis of those new words that were later remembered revealed greater activity in left frontal regions than those that were later forgotten-the same pattern of results as previously observed for traditional incidental and intentional episodic encoding tasks. This finding may offer a partial explanation for why repeated testing improves memory performance. Furthermore, the observation of correlates of episodic memory encoding during retrieval tasks challenges some interpretations that arise from direct comparisons between "encoding tasks" and "retrieval tasks" in imaging data. Encoding processes and their neural correlates may arise in many tasks, even those nominally labeled as retrieval tasks by the experimenter.

tasks require subjects to intentionally search back through memory and retrieve information associated with a specific time and setting (Tulving, 1983). Much like any other task that involves meaning-based elaboration upon items and associations among items, episodic retrieval tasks would be expected to encourage incidental episodic encoding. Tulving, Kapur, Craik, Moscovitch, and Houle (1994, p. 2016) note "that an act of retrieval, whether supported by episodic memory or semantic memory, frequently constitutes an input into episodic memory."

Nonetheless, while some discussion of the pervasiveness of episodic encoding processes has occurred, most analyses have typically not fully considered this possibility. Task comparisons have been categorically labeled as either primarily tapping encoding or retrieval with interpretation following from such binary classification (McDermott et al., 1999; Schacter \& Wagner, 1999; Lepage, Habib, \& Tulving, 1998; Gabrieli, Brewer, Desmond, \& Glover, 1997; Nyberg, Cabeza, \& Tulving, 1996; Tulving et al., 1994).

How can we move beyond such binary task classification to explore more fully those task processes and brain correlates that associate with memory encoding? One possible approach is to examine encoding processes in direct relation to how such processes influence subsequent memory. That is, those processes (or in neural terms, patterns of brain activity) that predict subsequent memory should be entertained as candidate processes (or brain areas) directly relevant to encoding-indepen- 


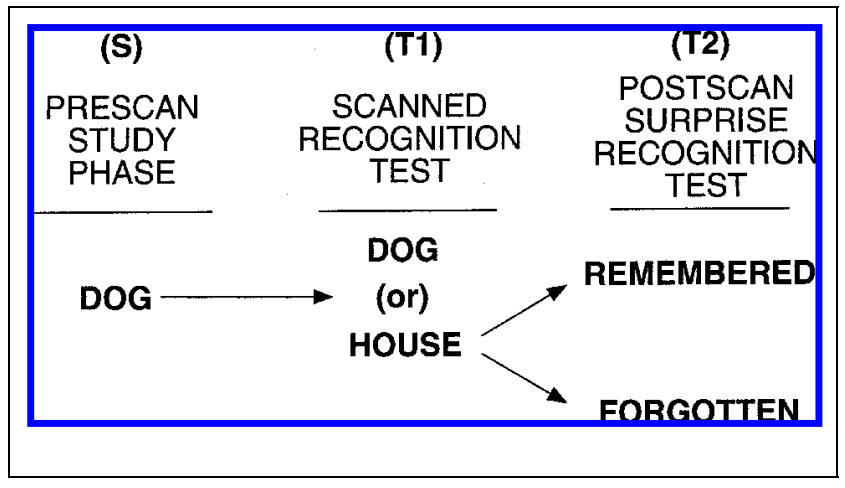

Figure 1. The design of the fMRI experiment is schematically illustrated. Subjects initially studied words such as "DOG" during a prescan study phase (S). During fMRI imaging, both old words (e.g., "DOG") and new words (e.g., "HOUSE") were individually presented and subjects performed an old/new recognition test (T1). Following imaging, a surprise postscan recognition test was administered (T2). The imaged new words were tested for subsequent memory-some were remembered and others were forgotten, allowing post hoc sorting to isolate neuronal correlates of encoding.

dent of the specific task context in which they arise. With such an approach, processes related to episodic encoding can be extracted from the many task processes related to task goal completion. In practice, such a procedure is implemented by examining the data collected at the time of encoding based on test phase results (as advocated by Halgren \& Smith, 1987; Paller, Kutas, \& Mayes, 1987; Fabiani, Karis, \& Donchin, 1986; for a review, see Rugg, 1995).

This approach has been employed in a recent series of fMRI and PET studies (Alkire, Haier, Fallon, \& Cahill, 1998; Brewer, Zhao, Glover, \& Gabrieli, 1998; Wagner et al., 1998; for a review, see Wagner, Koustaal, \& Schacter, 1999). Neural correlates of verbal and nonverbal episodic encoding processes were studied by sorting items during a study phase based on whether the items were remembered at a later test phase. Activity within specific frontal regions predicted (on average) which items would be remembered and even the quality of that memory (remember vs. know; Brewer et al., 1998). Thus, the data revealed that frontally mediated processes play a role in episodic encoding in addition to their role in online goal-oriented task completion (Buckner, Kelley, \& Petersen, 1999). Certain medial temporal regions also showed such a relation, while other regions that were critical to task completion (e.g., early visual cortex) did not predict subsequent memory performance.

Building from these earlier studies, an fMRI study is presented to make concrete the theoretical issues discussed above. Neural correlates of encoding processes were identified during an episodic memory retrieval task (1) to explore the basis of the Testing phenomenon and (2) to illustrate the pervasiveness of processes and neural correlates associated with episodic encoding. Specifically, subjects performed an intentional memor- ization task during a study phase (S). Then, an explicit retrieval task based on yes/no recognition was given (T1). Following this first retrieval task, a second, surprise recognition task was given for those foils experienced during the prior scanned retrieval task (T2). In this manner, the second retrieval task allowed the determination of which items experienced during the first retrieval task were remembered and which were forgotten.

In Experiment 1, we demonstrate behaviorally that retrieval promotes high levels of episodic encoding by manipulating whether a retrieval task or other, more typical, forms of encoding task was given at T1. In Experiment 2, we illustrate the neural correlates of encoding during the $\mathrm{T} 1$ retrieval task by using rapid-presentation event-related fMRI procedures (see Figure 1).

\section{RESULTS}

\section{Experiment 1: Behavioral Results}

Recognition task performance varied across encoding conditions: probability of a hit (pHIT) following intentional encoding $=.70$, following abstract/concrete discrimination (deep incidental encoding) $=.84$, following uppercase/lowercase discrimination (shallow incidental encoding) $=.47$, and following old/new recognition $=.74$. Probability of a false alarm (pFA) for all conditions $=.21$. Corrected recognition rates are plotted in Figure 2.

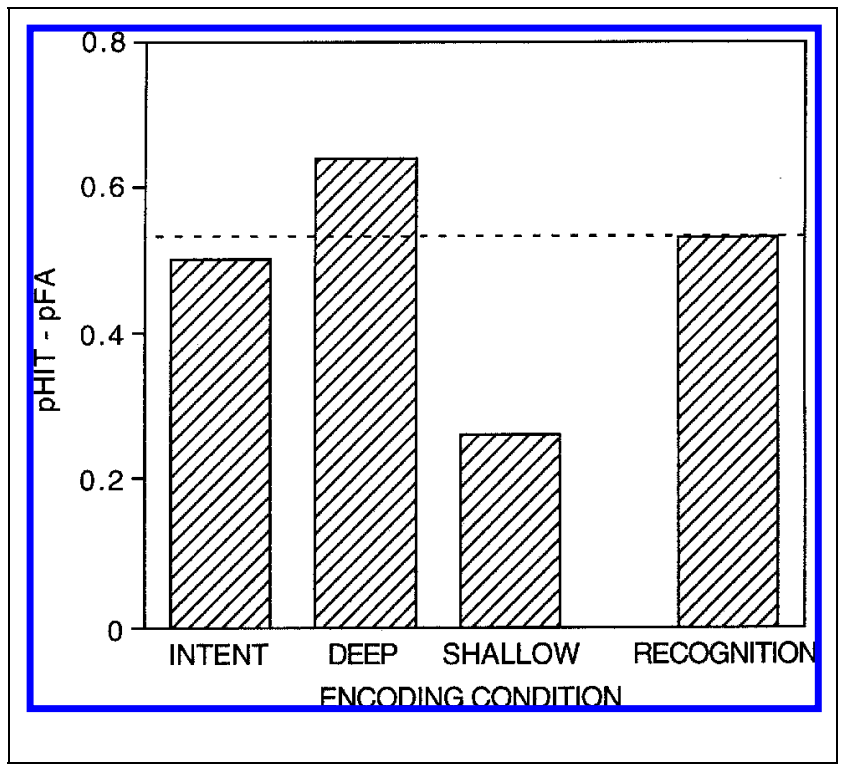

Figure 2. Results from Experiment 1 indicate recognition is an effective incidental-encoding task. Graphed are the corrected recognition rates for the final surprise memory test (T2) based on four encoding conditions at T1: intentional memorization (INTENT), abstract/concrete discrimination (DEEP), uppercase/lowercase discrimination (SHALLOW), and old/new recognition (RECOGNITION). The dashed line shows the performance following the old/new recognition encoding condition for reference. 
An ANOVA revealed a main effect of condition $[F(3,11)=11.14, p<.001]$. Of central importance, subsequent memory for words following the old/new recognition task was similar to that of the intentional memorization task and greater than that of the shallow incidental-encoding task. Post hoc $t$ tests confirmed these observations with corrected recognition following the old/new recognition test being significantly greater than that following shallow encoding $[t(11)=5.45, p<.001]$ and no different than either of the other two tasks. Performance following the abstract/concrete discrimination task was quantitatively greater than the old/new recognition task, but this effect was not significant. These results clearly suggest that old/new recognition is an effective incidentalencoding task.

\section{Experiment 2: Behavioral Results}

The recognition task performance during fMRI imaging was high: $\mathrm{pHIT}=.75$ and $\mathrm{pFA}=.12$. Thus, the corrected recognition rate ( $\mathrm{pHIT}-\mathrm{pFA})$ was .63.

Mean reaction times across subjects for the different trial types were HIT $=1049 \mathrm{msec}$, MISS = $1324 \mathrm{msec}$, $\mathrm{CR}=1129 \mathrm{msec}$, and FA $=1312 \mathrm{msec}$. These mean reaction times significantly differed based on ANOVA $[F(3,13)=17.03, p<.001]$ with both HIT responses being significantly faster than MISS responses $[t(13)=$ 4.64, $p<.001]$ and CR responses being significantly faster than FA responses $[t(13)=4.40, p<.001]$. HIT responses were not significantly faster than CR responses but showed a trend toward significance $[t(13)$ $=1.95, p=.07]$.

Of the new items (including both CR and FA trials) the majority were successfully recognized on the later postscan surprise test of recognition, paralleling the behavioral results of Experiment 1 (pHIT $=.64$ and $\mathrm{pFA}=.24$; $\mathrm{pHIT}-\mathrm{pFA}=.40)$. Performance was not quite as high as during Experiment 1 perhaps owing to the change from MR environment during study to behavioral chamber at test and/or the larger number of items encoded under the same condition in this experiment.

To provide insight into the influence of processing time on observed hemodynamic correlates, the new items during the initially scanned recognition task were divided based on their classification as used for MR data sorting. Mean reaction times were: "definitely old" $=1128$ msec, "probably old" = 1165 msec, "guess" = 1127 msec, "probably new" = $1123 \mathrm{msec}$, and "definitely new" = 1113 msec. Statistical analyses based on ANOVA including the subset of 10 subjects providing reaction times in all response categories (four subjects did not use one or more of the five classifications: e.g., some subjects never selected "guess") were not significant $[F(4,9)=.96, p=.44]$ and no post hoc comparisons reached significance. These results indicate that the amount of time spent on each recognition trial did not predict whether or not a word would be later remembered, alleviating some concerns with "time on task" or duty cycle confounds (D'Esposito et al., 1997).

\section{Experiment 2: fMRI Results}

Comparison of retrieval task trials (all trials included) to the low-level fixation reference trials revealed a distributed network of activated regions consistent with the multiple goals of the task (Figure 3, top). Occipital regions extending from areas near striate cortex to extrastriate cortex were active, almost certainly in response to the visual word processing demands. Left
Figure 3. Statistical activation maps from Experiment 2 show transverse sections of BOLD signal increase between all recognition trials versus fixation (top) and new items subsequently remembered versus those forgotten (bottom). The color scale reflects statistical significance as shown by the color bar to the right. Activation maps are overlaid on the averaged anatomic image across subjects. The section level (in the Talairach \& Tournoux, 1988 , atlas coordinates) is indicated by the $z$ value (in $\mathrm{mm}$ ) at the bottom.

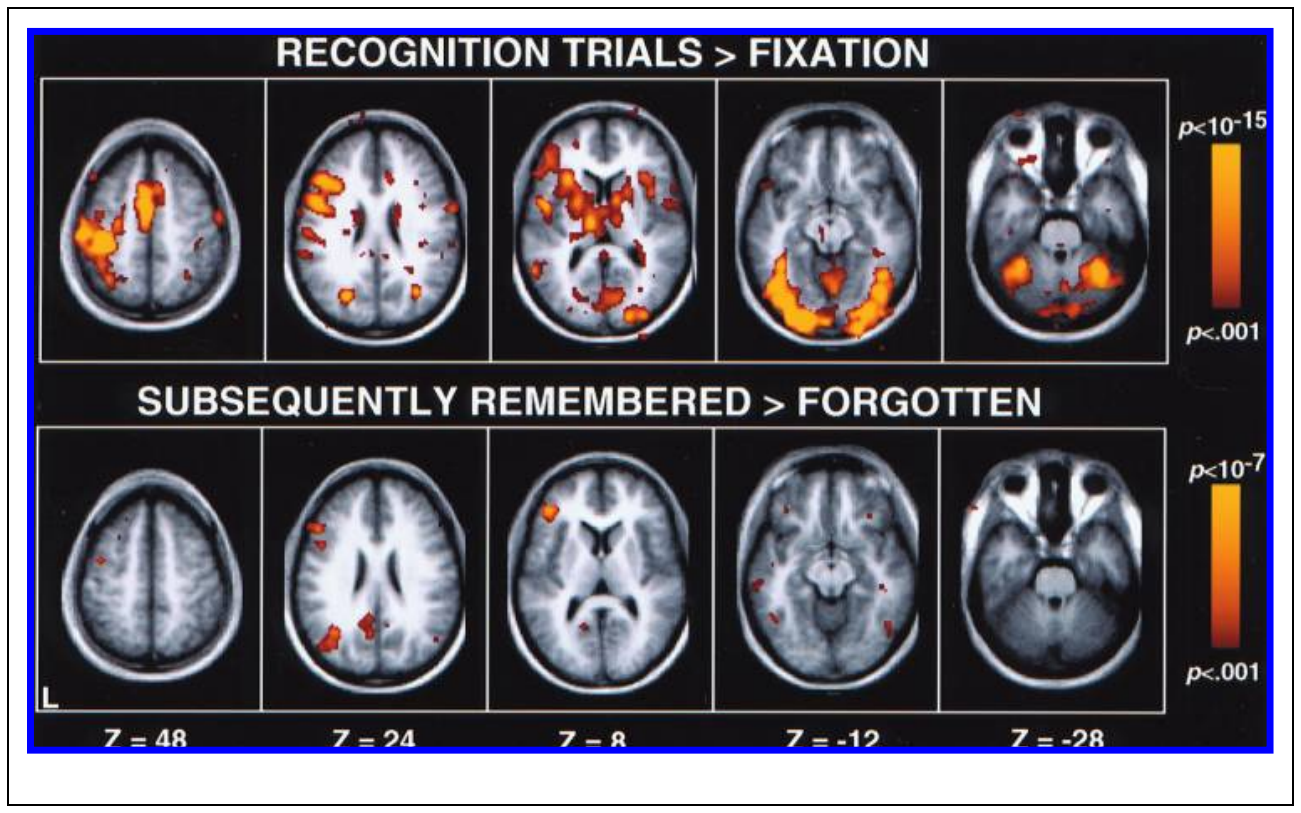


Table 1. Peak Locations Showing a Significant Effect of Subsequent Memory in Experiment 2

\begin{tabular}{|c|c|c|c|c|c|}
\hline \multicolumn{3}{|c|}{ Coordinates } & \multirow{2}{*}{$\begin{array}{c}\text { Significance } \\
-\log (p)\end{array}$} & \multicolumn{2}{|c|}{ Location } \\
\hline$x$ & $y$ & $z$ & & $B A$ & Anatomic Label \\
\hline-43 & 33 & 6 & 16.9 & $45 / 47$ & L. prefrontal \\
\hline-9 & 63 & 18 & 13.6 & 10 & Med. prefrontal \\
\hline-35 & -63 & 24 & 13.2 & 39 & L. parietal/occipital \\
\hline-43 & -75 & 18 & 12.8 & $19 / 39$ & L. parietal/occipital \\
\hline-49 & 23 & 24 & 12.6 & 46 & L. prefrontal \\
\hline-41 & -1 & 52 & 12.2 & $4 / 6$ & L. frontal \\
\hline-37 & -79 & 30 & 12.1 & 19 & L. parietal/occipital \\
\hline-39 & -1 & 30 & 10.9 & $6 / 44$ & L. frontal \\
\hline-5 & -63 & 26 & 10.7 & 31 & Med. precuneus \\
\hline-47 & 9 & 22 & 10.6 & $44 / 45$ & L. prefrontal \\
\hline-7 & -49 & 26 & 10.6 & 23 & Pos. cingulate gyrus \\
\hline 29 & -75 & 32 & 9.2 & 19 & R. parietal/occipital \\
\hline-47 & -63 & -8 & 8.8 & $19 / 37$ & L. occipital/temporal \\
\hline
\end{tabular}

Coordinates are from the Talairach and Tournoux (1988) atlas; R. = right; L. = left; Med. = medial; Pos. = posterior; BA = approximate Brodmann's area based on atlas coordinates.

motor cortex, supplementary motor area, and medial cerebellum were active presumably in response to the output (keypress) demands of the task. In addition to these sensory/motor regions, activated regions also included multiple frontal (mostly left lateralized), basal ganglia, thalamic, and anterior cingulate regions. This network of regions is highly similar to that observed in a number of previous episodic retrieval tasks (e.g., McDermott et al., 1999; Buckner, Koustaal, Schacter, Wagner, \& Rosen, 1998; Schacter, Buckner, Koustaal, Dale, \& Rosen, 1997; Haxby et al., 1996; Andreasen et al., 1995; Petrides, Alivisatos, \& Evans, 1995) and is largely similar for both old and new items (see Konishi, Wheeler, Donaldson, \& Buckner, 2000).

Most central to the theoretical issue of the present manuscript, a small number of regions showed differential activation for those new items experienced during the retrieval task that were subsequently remembered as compared to those subsequently forgotten (Figure 3, bottom; Table 1). These changes correlate with episodic encoding. Among the regions showing correlation were prominent activations within left frontal cortex along the superior and inferior extents of the inferior frontal gyrus. In addition, a region within the left inferior temporal cortex along the fusiform gyrus showed such an effect.

To examine more specifically the left frontal and inferior temporal regions, the time courses of the hemodynamic responses were examined (relative to fixation) for (1) new items subsequently remembered with high confidence (REMEMBERED) and (2) new items subsequently forgotten (FORGOTTEN). Results are shown in Figure 4.

\section{DISCUSSION}

Subjects were imaged while performing an episodic retrieval task. Unlike prior analyses of episodic retrieval tasks, the focus here was on subsequent memory for the new items experienced during the retrieval task. That is, the retrieval task was analyzed as an episodic encoding task. Subjects were tested on a surprise recognition test for the new (foil) items experienced during the first imaged recognition task. Much like typical incidental-encoding tasks, the episodic retrieval task encouraged encoding into long-term episodic memory: Subjects remembered well those new items experienced during the scanned recognition task. Results from an initial behavioral study (Experiment 1) revealed that encoding during retrieval was as good as that during an intentional memorization task and considerably better than during a shallow incidental-encoding task (Figure 2). Moreover, by sorting the new items in the imaged recognition task (Experiment 2) by whether the items were later remembered or forgotten revealed clear neuronal correlates of encoding into episodic memory (Figure 3, bottom).

Multiple regions extending along inferior frontal gyrus were more active for those items that were later remembered than those forgotten. The differential activation of these particular regions is consistent with a role in episodic memory encoding (see Buckner et al., 1999; 
Figure 4. The hemodynamic response is displayed for three separate regions: (A) a region along the dorsal extent of inferior frontal gyrus at or near Brodmann's area 44/6 (peak location in the Talairach \& Tournoux, 1988, atlas coordinates, $x, y, z=-49,23,24)$, (B) a region along the inferior extent of inferior frontal gyrus at or near Brodmann's area 44/ 45/47 ( $x, y, z=-43,33,6)$, and (C) a region in ventral occipitaltemporal cortex along fusiform gyrus $(x, y, z=-47,-63,-8)$. Voxels included in the regions are displayed to the left in each panel. The time courses to the right represent the mean percent MRI signal change for the REMEMBERED (filled circles) and FORGOTTEN (filled diamonds) trials separately.

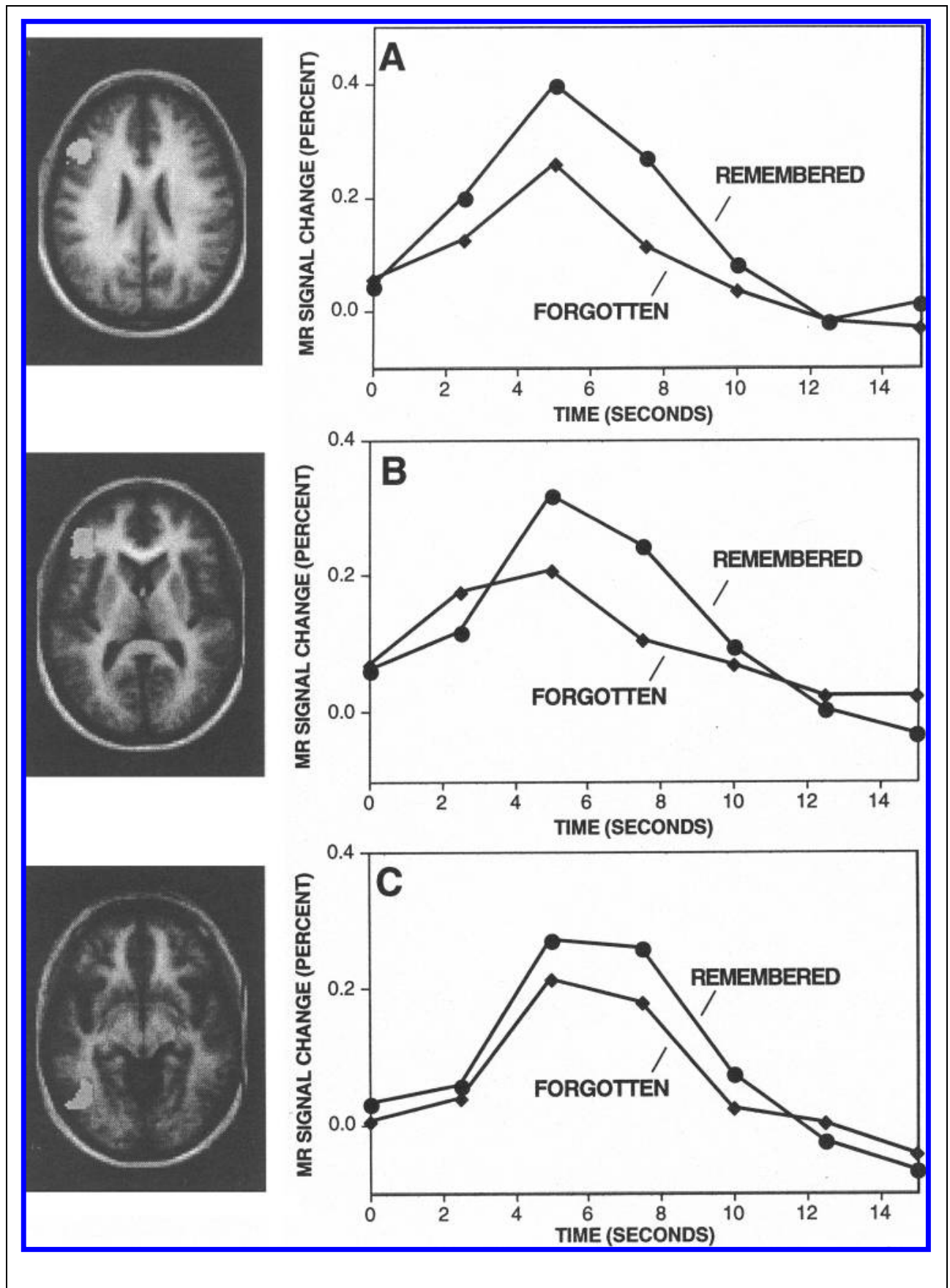

Cabeza \& Nyberg, 1997; Fletcher, Frith, \& Rugg, 1997; Tulving et al., 1994 for reviews). These results also parallel findings by Wagner et al. (1998) (see also Brewer et al., 1998) using a traditional incidental episodic encoding task. Wagner et al. noted that activity within these regions predicts subsequent retrieval task performance. It would appear that performance of an episodic retrieval task promotes deep encoding with the same neural mechanisms underlying encoding as would be found in traditional deep encoding tasks. There are several theoretical issues informed by these results.

First, the results suggest a neural mechanism for the Testing phenomenon in which taking an intervening test (a form of retrieval task) increases the likelihood of remembering materials on a final test (see Glover, 1989 for a review). The present results suggest retrieval tasks can be effective incidental-encoding tasks and engage frontally mediated processing resources that promote formation of an episodic memory. One caveat concerning such a statement is that interactions between retrieval and the history of the information being retrieved (e.g., whether it is old or new) are not fully considered here. Novel information (the focus of analysis in this manuscript) will likely show a greater degree of episodic encoding (Buckner, 2000; Tulving, Markowitsch, Craik, \& Habib, 1996; Jacoby \& Craik, 1979). 
The second issue informed by the present results relates to the broad consequences of encoding processes being pervasive across tasks, including retrieval tasks. On the one hand, such a finding makes intuitive sense. Many forms of experience that require elaboration upon information can promote episodic encoding. Simply because a task is labeled as a "retrieval task" by the experimenter should not change that principle. On the other hand, the finding forces us to refocus operational definitions of encoding and reevaluate conclusions generated from direct contrasts between "encoding" and "retrieval" tasks. That is, if tasks nominally labeled as retrieval tasks by the experimenter promote episodic encoding, what does it mean to isolate correlates of encoding in contrast to correlates of retrieval?

To discuss these issues it is worthwhile to distinguish two distinct kinds of processing effect: (1) those relating to the completion of immediate task demands and (2) those relating to the promotion of plasticity events that endure over time. Of importance to episodic memory formation, activity within certain regions may simultaneously relate to both effects (Buckner et al., 1999). By this view, the same initial processing event may serve to accomplish immediate task goals and also begin the cascade of neural events that allows an episodic memory to form.

Regarding the first kind of effect in the presently examined episodic retrieval task, the goal is (heuristically) to process the presented word cue to a level where its meaning is represented, relate the cue to information presented during a prior study episode, and decide whether or not the cue had previously been presented. Not surprisingly, a network of brain regions became active to support completion of these many component task demands (Figure 3, top). At one level of analysis, focus can be placed on the specific contributions of subsets of these regions to episodic memory retrieval-the immediate task goal (for a complementary analysis of these data in relation to processes correlated with successful episodic recovery, see Konishi et al., 2000). For the present purposes, we will not continue explicating possibilities along such lines.

While not intended by the subjects, a second distinct effect of the neural activity during the retrieval task was to promote modifications that endured over time and could be revealed at a later test phase. Thus, as suggested previously, retrieval constituted a new input to episodic memory (Tulving, 1983). Neural correlates of episodic encoding were revealed by sorting the new item trials based on whether they were remembered or forgotten on a subsequent explicit memory test. Activity within multiple left frontal regions along inferior frontal gyrus, lateral parietal cortex, and inferior temporal cortex along fusiform gyrus all correlated with episodic encoding. Among these regions, activity within similar left frontal and inferior temporal regions has been noted previously (e.g., Wagner et al., 1998) and may correlate with pro- cesses associated with elaboration upon word meaning. The present study did not demonstrate significant correlates of subsequent memory that extended into parahippocampal gyrus as in the original Wagner et al. study.

Speculatively, it would seem that processing of verbal information within specific regions of left frontal cortex leads to episodic memory formation-even if those representations are engendered in the context of an episodic retrieval task. The specific left frontal regions that predict subsequent memory are likely recruited during the retrieval task to aid in controlled processes associated with deciding whether a word is old or new, which likely encourages elaboration of the word's meaning and its relation to other words. Secondarily, the activity within these regions appears sufficient to begin a cascade of events that leads to long-term episodic encoding of the words (Buckner et al., 1999). Encoding processes are pervasive and will occur during certain retrieval tasks.

\section{METHODS}

\section{Subjects}

Twelve (six males) English-speaking subjects (ages 18 to 23 , mean age $=20.3$ years) participated in Experiment 1 in exchange for course credit or US $\$ 10$ payment. Fourteen (eight males) right-handed native English-speaking subjects (ages of 18 and 29, mean age $=24.1$ years) participated in the MRI part of Experiment 2 for payment (US $\$ 25 / \mathrm{hr}$ ). No subjects overlapped between the two experiments. Informed consent was obtained in a manner approved by the Washington University Human Studies Committee.

\section{Experiment 1: Behavioral Procedures}

The goal of the behavioral experiment was to determine to what degree an episodic retrieval task would encourage episodic encoding, replicating, and extending results from prior studies of the Testing phenomenon. For this study, subjects performed their tasks in a typical behavioral setting. Subjects sat in front of a computer monitor and viewed words presented via a PowerMacintosh computer (Apple Computer, Cupertino, CA), making keypress responses on a Psyscope Button Box (Cohen, MacWhinney, Flatt, \& Provost, 1993) or on the keyboard.

The procedure involved a series of four study-test $(\mathrm{S} 1 \rightarrow \mathrm{T} 1)$ cycles followed by a single final test phase (T2). Four conditions were manipulated within subject during the initial test (T1) phase, counterbalancing order of conditions between subjects.

Study (S) always involved intentional memorization of words. The first test condition (T1) manipulated four tasks including: (1) further intentional memorization, (2) abstract/concrete discrimination, (3) uppercase/low- 
ercase discrimination, and (4) old/new recognition. These four tasks collectively provide a standard intentional memorization instruction condition, a deep (abstract/concrete discrimination) and a shallow (uppercase/lowercase discrimination) incidental-encoding condition to be compared to the old/new recognition condition. The basic question was: Would the old/ new recognition condition promote episodic encoding? Performance during the second test (T2) provided data to directly answer this question.

For all conditions, words were presented centrally for 2000 msec (24-pt. bold Geneva font, white letters on a black background, $2500 \mathrm{msec}$ between stimulus onsets). Words came from one of 20 lists of 25 words each. Lists were balanced for word length (range $=4.68$ to 5.16 letters) and word frequency (range $=38.68$ to 38.96 appearances per million based on Kucera \& Francis, 1967). Four filler words were included at the beginning and end of each study (S) to minimize recency and primacy effects.

During each of the four initial test conditions (T1) subjects viewed 75 word items (25 old, 50 new) and performed one of the four tasks. (1) "Intentional memorization": Subjects were instructed to memorize the words and were told they would be tested on them at a later time. (2) "Abstract/concrete discrimination": Subjects indicated by button press whether the words represented abstract entities not physically found in the world (e.g., triumph) or concrete entities that could be found in the physical world (e.g., anvil). Subjects were further instructed to ignore whether the words were old or new as it was irrelevant to their abstract/concrete decision. (3) "Uppercase/lowercase discrimination": Subjects indicated whether the words were in uppercase or lowercase letters ignoring whether the words were old or new. (4) "Old/new recognition": Subjects indicated whether the words were old (previously presented) or new (not previously presented).

Following all $\mathrm{T} 1$ conditions, a break of $10 \mathrm{~min}$ was given. Then, the final test (T2) was administered to determine whether subjects encoded the new words presented during the various T1 conditions. Only the previously new words were tested enabling effects of the T1 encoding conditions to be examined without confounding the number of repetitions. The final T2 test involved one extended self-paced block where each item was judged, using a confidence scale, as to whether it was definitely old (DO), probably old (PO), guess $(\mathrm{G})$, probably new (PN), or definitely new (DN). 400 words were tested including 200 previously presented words (50 from each $\mathrm{T} 1$ condition) and 200 foils (entirely new words). The confidence scale was used in order to parallel that of the MR study below. Corrected recognition performance was computed for the four conditions with responses of either confidence level considered old or new responses and guess responses omitted.

\section{Experiment 2: Magnetic Resonance Procedures}

Imaging was performed on a 1.5-T Siemens Vision System (Erlanger, Germany). Subjects' heads were immobilized with cushions and plastic face-masks to reduce motion artifact.

For each subject, conventional structural images were first collected to provide detailed anatomic information. Then, a series of echo-planar functional image runs sensitive to blood oxygenation level-dependent (BOLD) contrast (Kwong et al., 1992; Ogawa et al., 1992) were acquired. The entire session, including both structural and functional imaging, lasted about $2 \mathrm{hr}$. During the middle portion of the session, an independent experiment involving a source memory retrieval task was performed. All methods pertain only to the experiments included in this article.

Structural imaging included a scout image to center the field of view on the subject's brain. Then, a highresolution structural T1-weighted image was acquired (MPRAGE sequence; $\mathrm{TR}=9.7 \mathrm{msec}, \mathrm{TE}=4 \mathrm{msec}$, flip angle $=10^{\circ}$, TI $=20 \mathrm{msec}$, TD $=500 \mathrm{msec}$ ). Echoplanar imaging consisted of collecting sequential T2* weighted functional image runs (asymmetric spin echo sequence; $\mathrm{TR}=2.50 \mathrm{sec} ; \mathrm{T} 2 *$ evolution time $=50$ $\mathrm{msec}$ ). Functional image runs consisted of 110 sequential whole-brain acquisitions (16 slices, in-plane resolution $3.75 \mathrm{~mm}, 8 \mathrm{~mm}$ slice thickness, no skip between slices, acquisition aligned to the plane intersecting the anterior and posterior commissures). Prior to each run, four image acquisitions were acquired to allow longitudinal magnetization to reach equilibrium. The first of these four image acquisitions was used to align the data to the high-resolution T1-weighted anatomy image.

All functional image runs were first preprocessed. Each volume within each run was corrected for odd/ even slice intensity differences and then motion-corrected between volumes using a rigid body rotation and translation correction (Snyder, 1996). To account for between-slice timing differences (induced by differences in acquisition order), the data were interpolated (using ideal sync interpolation) to be aligned in time to the midpoint of the first acquired slice. The linear slope was removed on a voxel-by-voxel basis to accommodate linear drift. Then, each subject's whole brain signal intensity was normalized to 1000. An in-plane spatial Hanning filter (radius $=1$ voxel) was applied. Finally, anatomic and functional data for each subject were placed in stereotaxic atlas space (Talairach \& Tournoux, 1988) using previously described procedures (McDermott et al., 1999). Reconstructed atlas voxel size was $2 \times$ $2 \times 2 \mathrm{~mm}$.

\section{Experiment 2: Behavioral Procedures}

Visual stimuli were presented to subjects by projecting (Ampro model LCD-150) the stimulus image onto a 
screen at the back of the magnet bore. Subjects viewed the screen through a mirror attached to the head coil. A custom-designed magnet-compatible keypress based on a fiber optic switch was used to record subject performance and reaction times on an Apple PowerMacintosh computer (Apple Computer).

Prior to each of the four separate fMRI functional runs, subjects viewed words and performed an intentional memorization task (equivalent to the initial study $S$ in Experiment 1). Words were presented centrally for 2000 msec (24-pt. bold Geneva font, white letters on a black background, 2500 msec between stimulus onsets). Twenty word lists of 25 words each from Experiment 1 were used. During each fMRI functional run, subjects performed a yes/no recognition task for the earlier studied items. The study-to-test delay was approximately $3 \mathrm{~min}$. For these runs, three trial types were presented in a continuous series of 100 intermixed trials over approximately $4 \mathrm{~min}$. Trial presentation was aligned to the beginning of each image acquisition (one trial every $2500 \mathrm{msec}$; word duration $=2000 \mathrm{msec}$ ). Trial types were: (1) new items, (2) old items from the earlier study list, or (3) a fixation cross hair (a small "+" symbol). Using procedures described in Buckner, Goodman, et al. (1998) and Miezin, Maccotta, Ollinger, Petersen, and Buckner (2000), trial types were pseudorandomly intermixed forcing counterbalancing of order between trial types. There were 50 new, 25 old, and 25 fixation trials per run for a total of 200 new, 100 old, and 100 fixation trials across runs. Subjects were instructed to decide whether the word was old or new by pressing a key with their right hand "as quickly and accurately as possible." Each functional run began with $10 \mathrm{sec}$ and ended with $15 \mathrm{sec}$ of visual fixation. Across subjects, word lists were counterbalanced such that new items for one subject were old items for another subject.

After the scanning session, subjects were brought to a second room where a surprise memory test was given in a manner analogous to $\mathrm{T} 2$ of the behavioral part of Experiment 1 . The delay between the last functional run and the surprise memory test was approximately $10 \mathrm{~min}$. For this test, the 200 previously "New" items from the scanned recognition test were presented along with 200 foils (entirely new items) and tested in the same manner as in behavioral part of Experiment 1.

\section{Event-Related fMRI Procedures}

The goal of the event-related procedures was to sort the recognition task word items based on whether new long-term episodic encoding took place. Specifically, the new items during the scanned recognition test were sorted based on whether they were subsequently remembered or forgotten at the second postscan recognition test (Figure 1).

The procedures for sorting (selective averaging) the data and statistical map generation have been described previously (Buckner, Goodman, et al., 1998; Dale \& Buckner, 1997). Briefly, the preprocessed fMRI runs in stereotaxic atlas space were selectively averaged within each subject such that eight mean images (20 sec at TR $=2500 \mathrm{msec}$ ) were retained for each trial type, as well as the variance for each of the eight images per trial type. Five trial types were included: (1) fixation, (2) old items, (3) new items that were subsequently forgotten, (4) new items that were subsequently remembered with low confidence (that is, subsequently endorsed as probably old), and (5) new items that were subsequently remembered with high confidence (that is, subsequently endorsed as definitely old).

Activation maps contrasting the various trial types were constructed using a $t$ statistic as described by Dale and Buckner (1997). For this analysis, a set of predicted hemodynamic curves was generated with the onset delay of the hemodynamic response varied over time. Specifically, gamma functions were used as the base shape with fixed parameters $\delta=2500 \mathrm{msec}$ and $\tau=$ 1250 msec (see Dale \& Buckner, 1997; Boynton, Engel, Glover, \& Heeger, 1996) and a latency delay parameter that contained 15 values each at 1 -sec steps.

Statistical maps were generated based on the differences between trial types. Difference time-courses were examined because, given the short intertrial interval (2500 $\mathrm{msec}$ ) and the relatively long length of the hemodynamic response, the raw unsubtracted time-courses were dominated by overlap between adjacent trials. Counterbalancing the trial orders, in combination with the fact that subjects' responses are fairly random over trials, allowed the direct subtraction between trial events to cancel out the between-trial overlap (Buckner, Goodman, et al., 1998; Dale \& Buckner, 1997).

Having constructed statistical activation maps, peak activation coordinates in Talairach and Tournoux (1988) atlas space were generated using the constraint that only peaks significant at the $p<.001$ level and in clusters of 19 or more significant voxels $\left(152 \mathrm{~mm}^{3}\right)$ were considered. When peaks were identified within $12 \mathrm{~mm}$ of one another, only the most significant was kept. This statistical threshold, which is based on a fixed-effect model, matches that verified previously to yield few false positives taking into account temporally autocorrelation between adjacent time points (Buckner, Goodman, et al., 1998; using the empirical procedure of Zarahn, Aguirre, \& D'Esposito, 1997). To be certain that this statistical threshold is appropriate, a further analysis beyond that of Buckner, Goodman, et al. (1998) was performed to verify false positive rates. For this analysis, 12 additional subjects were asked to fixate on a visual cross hair for the duration of two fMRI functional image runs. Scanning parameters were similar to those above but no task trials were presented. These control data were then analyzed in the same manner as the actual task data. No activations (false positives) were detected at the specified criterion. 
Regional analysis was performed by using the identified peak locations as seed points for automatic region definition. Specifically, all voxels within $12 \mathrm{~mm}$ of a peak location that were more significant than $p<.001$ were included in the region. The mean signal intensity (in percent change) over the 20 -sec response epochs was computed for each event type. The baseline fixation epoch was subtracted from each trial event type to obtain a mean regional hemodynamic response estimate that was corrected for overlap between sequential trials. The resultant time course was then baseline shifted to a set baseline value of zero.

\section{Acknowledgments}

We thank David Donaldson for help with data collection, Laura Williams for assistance in manuscript preparation, and Erbil Akbudak, Abraham Snyder, and Thomas Conturo for the support and development of the MRI procedures. Luigi Maccotta and Anders Dale provided assistance in eventrelated software and analysis development. Roberto Cabeza, Wilma Koutstaal, Endel Tulving, Deanna Barch, Henry Roediger, Lars Nyberg, and two anonymous reviewers provided valuable comments during the evolution of this manuscript. This work was supported by grants from the McDonnell Center for Higher Brain Function (to RLB), NIH grants MH57506 (to RLB) and NS32979 (to Steven E. Petersen), and a James S. McDonnell Foundation Program in Cognitive Neuroscience grant (99-63/9900003 to RLB).

The data reported in this experiment have been deposited in the National fMRI Data Center (http://www.fmridc.org). The accession number is 2-2001-111GQ.

Reprint requests should be sent to: Dr. Randy L. Buckner, Department of Psychology, Washington University, Campus Box 1125, One Brookings Drive, St. Louis, MO 63130, USA. Tel.: +1-314-935-5019; fax: +1-314-935-7588; e-mail: rbuckner@artsci.wustl.edu.

\section{REFERENCES}

Alkire, M. T., Haier, R. J., Fallon, J. H., \& Cahill, L. (1998). Hippocampal, but not amygdala, activity at encoding correlates with long-term, free recall of nonemotional information. Proceedings of the National Academy of Sciences, U.S.A., 95, 14506-14510.

Andreasen, N. C., O'Leary, D. S., Ardnt, S., Cizadlo, T., Hurtig, R., Rezai, K., Watkins, G. L., Boles Ponto, L. L., \& Hichwa, R. D. (1995). Short-term and long-term verbal memory: A positron emission tomography study. Proceedings of the National Academy of Sciences, U.S.A., 92, 5111-5115.

Boynton, G. M., Engel, S. A., Glover, G. H., \& Heeger, D. J. (1996). Linear systems analysis of functional magnetic resonance imaging in human V1. Journal of Neuroscience, 16, 4207-4221.

Brewer, J. B., Zhao, Z., Glover, G. H., \& Gabrieli, J. D. E. (1998). Parahippocampal and frontal responses to single events predict whether those events are remembered or forgotten. Science, 281, 1185-1187.

Buckner, R. L. (2000). Neuroimaging of memory. In M. S. Gazzaniga (Ed.), The new cognitive neurosciences (pp. 817828). Cambridge: MIT Press.

Buckner, R. L., Goodman, J., Burock, M., Rotte, M., Koutstaal, M., Schacter, D. L., Rosen, B., \& Dale, A. M. (1998). Func- tional-anatomic correlates of object priming in humans revealed by rapid presentation event-related fMRI. Neuron, 20, 285-296.

Buckner, R. L., Koutstaal, W., Schacter, D. L., Wagner, A. D., \& Rosen, B. R. (1998). Functional-anatomic study of episodic retrieval using fMRI: I. Retrieval effort versus retrieval success. Neuroimage, 7, 151-162.

Buckner, R. L., Kelley, W. M., \& Petersen, S. E. (1999). Frontal cortex contributes to human memory formation. Nature Neuroscience, 2, 311-314.

Cabeza, R., \& Nyberg, L. (1997). Imaging cognition: An empirical review of PET studies with normal subjects. Journal of Cognitive Neuroscience, 9, 1-26.

Cohen, J. D., MacWhinney, B., Flatt, M., \& Provost, J. (1993). PsyScope: A new graphic interactive environment for designing psychology experiments. Behavioral Research Methods, Instruments, and Computers, 25, 257-271.

Craik, F. I. M., \& Lockhart, R. S. (1972). Levels of processing: A framework for memory research. Journal of Verbal Learning and Verberal Behavior, 11, 671-684.

Craik, F. I. M., \& Tulving, E. (1975). Depth of processing and the retention of words in episodic memory. Journal of Experimental Psychology: General, 104, 168-294.

Dale, A. M., \& Buckner, R. L. (1997). Selective averaging of rapidly presented individual trials using fMRI. Human Brain Mapping, 5, 329-340.

D'Esposito, M., Zarahn, E., Aguirre, G. K., Shin, R. K., Auerbach, P., \& Detre, J. A. (1997). The effect of pacing of experimental stimuli on observed functional MRI activity. Neuroimage, 6 , 113-121.

Fabiani, M., Karis, M., \& Donchin, E. (1986). P300 and recalling an incidental memory paradigm. Psychophysiology, 23, 298308.

Fletcher, P. C., Frith, C. D., \& Rugg, M. D. (1997). The functional neuroanatomy of episodic memory. Trends in Neuroscience, 20, 213-218.

Gabrieli, J. D. E., Brewer, J. B., Desmond, J. E., \& Glover, G. H. (1997). Separate neural bases of two fundamental memory processes in the human medial temporal lobe. Science, 276, 264-266.

Glover, J. A. (1989). The “Testing” phenomenon: Not gone but nearly forgotten. Journal of Educational Psychology, 81, 392-399.

Halgren, E., \& Smith, M. E. (1987). Cognitive evoked potentials as modulatory processes in human memory formation and retrieval. Human Neurobiology, 6, 129-139.

Haxby, J. V., Ungerleider, L. G., Horwitz, B., Maisog, J. M., Rapoport, S. L., \& Grady, C. L. (1996). Face encoding and recognition in the human brain. Proceedings of the National Academy of Sciences, U.S.A., 93, 922-927.

Hyde, T. S., \& Jenkins, J. J. (1973). Recall of words as a function of semantic, graphic, and syntactic orienting tasks. Journal of Verbal Learning and Verbal Behavior, 12, 471-480.

Jacoby, L. L., \& Craik, F. I. (1979). Effects of elaboration of processing at encoding and retrieval: Trace distinctiveness and recovery of initial context. In L. S. Cermak, \& F. I. M. Craik (Eds.), Levels of processing in buman memory (pp. 1-22). Hillsdale, NJ: Erlbaum.

Klee, H., \& Gardiner, J. M. (1976). Memory for remembered events: Contrasting recall and recognition. Journal of Verbal Learning and Verbal Behavior, 15, 471-478.

Konishi, S, Wheeler, M. E., Donaldson, D. I., \& Buckner, R. L. (2000). Neuronal correlates of episodic retrieval success. Neuroimage, 12, 276-286.

Kucera, H., \& Francis, W. (1967). Computational analysis of present-day American English. Providence, RI: Brown University Press. 
Kwong, K. K., Belliveau, J. W., Chesler, D. A., Goldberg, I. E., Weisskoff, R. M., Poncelet, B. P., Kennedy, D. N., Hoppel, B. E., Cohen, M. S., \& Turner, R. (1992). Dynamic magnetic resonance imaging of human brain activity during primary sensory stimulation. Proceedings of the National Academy of Sciences, U.S.A., 89, 5675-5679.

Lepage, M., Habib, R., \& Tulving, E. (1998). Hippocampal PET activations of memory encoding and retrieval: The HIPER model. Hippocampus, 8, 313-322.

McDermott, K. B., Ojemann, J. G., Petersen, S. E., Ollinger, J. M., Snyder, A. Z., Akbudak, E., Conturo, T. E., \& Raichle, M. E. (1999). Direct comparison of episodic encoding and retrieval of words: An event-related fMRI study. Memory, 7, 661-678.

Miezin, F. M., Maccotta, L., Ollinger, J. M., Petersen, S. E., \& Buckner, R. L. (2000). Characterizing the hemodynamic response: Effects of presentation rate, sampling procedure, and the possibility of ordering brain activity based on relative timing. Neuroimage, 11, 735-759.

Nyberg, L., Cabeza, R., \& Tulving, E. (1996). PET studies of encoding and retrieval: The HERA model. Psychonomic Bulletin and Review, 3, 135-148.

Ogawa, S., Tank, D. W., Menon, R., Ellerman, J. M., Kim, S. G., Merkle, H., \& Ugurbil, K. (1992). Intrinsic signal changes accompanying sensory stimulation: Functional brain mapping with magnetic resonance imaging. Proceedings of the National Academy of Sciences, U.S.A., 89, 5951-5955.

Paller, K. A., Kutas, M., \& Mayes, A. R. (1987). Neural correlates of encoding in an incidental learning paradigm. Electroencephalography and Clinical Neurophysiology, 67, 360-371.

Petrides, M., Alivisatos, B., \& Evans, A. C. (1995). Functional activation of the human ventrolateral frontal cortex during mnemonic retrieval of verbal information. Proceedings of the National Academy of Sciences, U.S.A., 92, 5803-5807.

Postman, L. (1964). Short-term memory and incidental learning. In A. W. Melton (Ed.), Categories of human learning (pp. 146-201). New York: Academic Press.

Roediger, H. L., \& Payne, D. G. (1982). Hypermnesia: The role of repeated testing. Journal of Experimental Psychology: Learning, Memory, and Cognition, 8, 66-72.

Rugg, M. D. (1995). ERP studies of memory. In M. D. Rugg, \& M. G. H. Coles (Eds.), Electrophysiology of mind: Event-related brain potentials and cognition (pp. 132-170). Oxford: Oxford University Press.
Schacter, D. L., \& Wagner, A. D. (1999). Medial temporal lobe activations in FMRI and PET studies of episodic encoding and retrieval. Hippocampus, 9, 7-24.

Schacter, D. L., Buckner, R. L., Koutstaal, W., Dale, A. M., \& Rosen, B. R. (1997). Late onset of anterior prefrontal activity during true and false recognition: An event-related fMRI study. Neuroimage, 6, 259-269.

Snyder, A. Z. (1996). Difference image versus ratio image error function forms in PET-PET realignment. In D. Bailey, \& T. Jones (Eds.), Quantification of brain function using PET. (pp. 131-137). San Diego: Academic Press.

Talairach, J., \& Tournoux, P. (1988). Co-planar stereotaxic atlas of the buman brain. New York: Thieme.

Tulving, E. (1983). Elements of episodic memory. New York: Oxford University Press.

Tulving, E., Kapur, S., Craik, F. I. M., Moscovitch, M., \& Houle, S. (1994). Hemispheric encoding/retrieval asymmetry in episodic memory: Positron emission tomography findings. Proceedings of the National Academy of Sciences, U.S.A., 91, 2016-2020.

Tulving, E., Markowitsch, H. J., Craik, F. I., \& Habib, R. (1996). Novelty and familiarity activations in PET studies of memory encoding and retrieval. Cerebral Cortex, 6, 71-79.

Wagner, A. D., Schacter, D. L., Rotte, M., Koutstaal, W., Maril, A., Dale, A. M., Rosen, B. R., \& Buckner, R. L. (1998). Building memories: Remembering and forgetting of verbal experiences as predicted by brain activity. Science, 281, 1188-1191.

Wagner, A. D., Koustaal, W., \& Schacter, D. L. (1999). When encoding yields remembering: Insights from event-related neuroimaging. Philosophical Transactions of the Royal Society of London, 354, 1307-1324.

Walsh, D. A., \& Jenkins, J. J. (1973). Effects of orienting tasks on free recall in incidental learning: "Difficulty," "effort," and "process" explanations. Journal of Verbal Learning and Verbal Behavior, 12, 481-488.

Whitten, W. B. (1978). Initial-retrieval "depth" and the negative recency effect. Memory and Cognition, 6, 590-598.

Whitten, W. B., \& Bjork, R. A. (1977). Learning from tests: Effects of spacing. Journal of Verbal Learning and Verbal Behavior, 16, 465-478.

Zarahn, E., Aguirre, G. K., \& D’Esposito, M. (1997). Empirical analyses of BOLD fMRI statistics: I. Spatially unsmoothed data collected under null-hypothesis conditions. Neuroimage, 5, 179-197. 


\section{This article has been cited by:}

1. V. G Carrion, B. W Haas, A. Garrett, S. Song, A. L Reiss. 2010. Reduced Hippocampal Activity in Youth with Posttraumatic Stress Symptoms: An fMRI Study. Journal of Pediatric Psychology . [CrossRef]

2. Patricia T Alpert, Sally K Miller, Harvey Wallmann, Richard Havey, Chad Cross, Theresa Chevalia, Carrie B Gillis, Keshavan Kodandapari. 2009. The effect of modified jazz dance on balance, cognition, and mood in older adults. Journal of the American Academy of Nurse Practitioners 21:2, 108-115. [CrossRef]

3. Sarah Steinvorth, Chunmao Wang, Istvan Ulbert, Donald Schomer, Eric Halgren. 2009. Human entorhinal gamma and theta oscillations selective for remote autobiographical memory. Hippocampus NA-NA. [CrossRef]

4. Sina Kuehnel, Markus Mertens, Friedrich G. Woermann, Hans J. Markowitsch. 2008. Brain Activations During Correct and False Recognitions of Visual Stimuli: Implications for Eyewitness Decisions on an fMRI Study Using a Film Paradigm. Brain Imaging and Behavior 2:3, 163-176. [CrossRef]

5. Pascale Piolino, Béatrice Desgranges, Valérie Hubert, Frédéric A. Bernard, Vanessa Matuszewski, Gaël Chételat, Jean-Claude Baron, Francis Eustache. 2008. Reliving lifelong episodic autobiographical memories via the hippocampus: A correlative resting PET study in healthy middle-aged subjects. Hippocampus 18:5, 445-459. [CrossRef]

6. Melina R. Uncapher, Michael D. Rugg. 2008. Fractionation of the Component Processes Underlying Successful Episodic Encoding: A Combined fMRI and Divided-attention StudyFractionation of the Component Processes Underlying Successful Episodic Encoding: A Combined fMRI and Divided-attention Study. Journal of Cognitive Neuroscience 20:2, 240-254. [Abstract] [PDF] [PDF Plus]

7. S.L. Danckert, J.S. Gati, R.S. Menon, S. Köhler. 2007. Perirhinal and hippocampal contributions to visual recognition memory can be distinguished from those of occipito-temporal structures based on conscious awareness of prior occurrence. Hippocampus 17:11, 1081-1092. [CrossRef]

8. Thomas W. McAllister, Laura A. Flashman, Brenna C. McDonald, Andrew J. Saykin. 2006. Mechanisms of Working Memory Dysfunction after Mild and Moderate TBI: Evidence from Functional MRI and Neurogenetics. Journal of Neurotrauma 23:10, 1450-1467. [CrossRef]

9. Rutger Goekoop, Frederik Barkhof, Erik J J Duschek, Coen Netelenbos, Dirk L Knol, Philip Scheltens, Serge ARB Rombouts. 2006. Raloxifene Treatment Enhances Brain Activation during Recognition of Familiar Items: a Pharmacological fMRI Study in Healthy Elderly Males. Neuropsychopharmacology 31:7, 1508-1518. [CrossRef]

10. P. V. Rekkas , R. Todd Constable . 2005. Evidence That Autobiographic Memory Retrieval Does Not Become Independent of the Hippocampus: An fMRI Study Contrasting Very Recent with Remote EventsEvidence That Autobiographic Memory Retrieval Does Not Become Independent of the Hippocampus: An fMRI Study Contrasting Very Recent with Remote Events. Journal of Cognitive Neuroscience 17:12, 1950-1961. [Abstract] [PDF] [PDF Plus]

11. Jeffrey R. Binder, Patrick S. F. Bellgowan, Thomas A. Hammeke, Edward T. Possing, Julie A. Frost. 2005. A Comparison of Two fMRI Protocols for Eliciting Hippocampal Activation. Epilepsia 46:7, 1061-1070. [CrossRef]

12. Charan Ranganath, Michael X. Cohen , Craig J. Brozinsky . 2005. Working Memory Maintenance Contributes to Long-term Memory Formation: Neural and Behavioral EvidenceWorking Memory Maintenance Contributes to Long-term Memory Formation: Neural and Behavioral Evidence. Journal of Cognitive Neuroscience 17:7, 994-1010. [Abstract] [PDF] [PDF Plus]

13. Julia Sluzenski, Nora Newcombe, Wendy Ottinger. 2004. Changes in reality monitoring and episodic memory in early childhood. Developmental Science 7:2, 225-245. [CrossRef]

14. Sander M. Daselaar, Dick J. Veltman, Menno P. Witter. 2004. Common pathway in the medial temporal lobe for storage and recovery of words as revealed by event-related functional MRI. Hippocampus 14:2, 163-169. [CrossRef]

15. Eric E. Nelson, Erin B. McClure, Christopher S. Monk, Eric Zarahn, Ellen Leibenluft, Daniel S. Pine, Monique Ernst. 2003. Developmental differences in neuronal engagement during implicit encoding of emotional faces: an event-related fMRI study. Journal of Child Psychology and Psychiatry 44:7, 1015-1024. [CrossRef]

16. Chun-Siong Soon, Vinod Venkatraman, Michael W.L. Chee. 2003. Stimulus repetition and hemodynamic response refractoriness in event-related fMRI. Human Brain Mapping 20:1, 1-12. [CrossRef]

17. Rajendra D. Badgaiyan, Alan J. Fischman, Nathaniel M. Alpert. 2003. Striatal dopamine release during unrewarded motor task in human volunteers. NeuroReport 14:11, 1421-1424. [CrossRef]

18. Michael D. Greicius, Ben Krasnow, Jesse M. Boyett-Anderson, Stephan Eliez, Alan F. Schatzberg, Allan L. Reiss, Vinod Menon. 2003. Regional analysis of hippocampal activation during memory encoding and retrieval: fMRI study. Hippocampus 13:1, $164-174$. [CrossRef] 
19. Takashi Tsukiura, Toshikatsu Fujii, Reiko Fukatsu, Taisuke Otsuki, Jiro Okuda, Atsushi Umetsu, Kyoko Suzuki, Michio Tabuchi, Isao Yanagawa, Tatsuo Nagasaka, Ryuta Kawashima, Hiroshi Fukuda, Shoki Takahashi, Atsushi Yamadori. 2002. Neural Basis of the Retrieval of People's Names: Evidence from Brain-Damaged Patients and fMRINeural Basis of the Retrieval of People's Names: Evidence from Brain-Damaged Patients and fMRI. Journal of Cognitive Neuroscience 14:6, 922-937. [Abstract] [PDF] [PDF Plus] 